\title{
Development of social and communicative competence of a future teacher in the process of professional training
}

\author{
I.V. Zotova ${ }^{1 *}$ \\ ${ }^{1}$ State Budget Educational Institution of Higher Education of the Republic of Crimea Crimean \\ Engineering and Pedagogical University the name of Fevzi Yakubov, Simferopol, Russia
}

\begin{abstract}
The article is devoted to the problem of developing social and communicative competence of future teachers in the process of their professional training. The definition of the concepts of "social and communicative competence", "professional training of a teacher" is given. The development of the social and communicative competence of a future teacher in the process of his professional training, which is understood as an integral neoformation of a teacher's personality, being characterized by a set of theoretical, linguistic and methodological knowledge on the development of social and communicative competence of future teachers in the process of his professional training, was considered. Pedagogical conditions for the development of social and communicative competence of future teachers in the process of their professional training were revealed. The results of the experimental work showed that if the pedagogical conditions are observed, future teachers in educational organizations have an increased desire to develop social and communicative competences and strive for achieving effective skills of interpersonal interaction and communication, as well as for knowledge of the methodological foundations and categories of pedagogy, patterns of development and formation of students' personalities.
\end{abstract}

\section{A problem statement}

Implementation of modern educational policy is possible in the conditions of training of future teachers, focused not only on obtaining systems of psychological and pedagogical knowledge and skills, but also on the development of social and communicative competence and professionally significant personal qualities.

Socio-communicative competence is defined as an ability to collective action, organization of interaction involving interpersonal skills, and a desire for social interaction.

Communication (the social one) should be understood as effective synchronous and diachronous interaction of social subjects (people and (or) their communities), the essence of which is the movement from one subject (source) to another (recipient) of information

\footnotetext{
${ }^{*}$ Corresponding author: ipcs-profped@yandex.ru
} 
that has meaning for them (communication substance or message) in ideal or ideal material form).

Based on the idea that any relationship is essentially a socio-communicative phenomenon, we believe that social communication is the goal-oriented actions of two or more subjects that carry out the formation, transmission, processing, mastering and transformation of social information using special mechanisms and means (language, behavioral forms, including Internet communications); they are accompanied by the movement of meanings in social time and space.

\subsection{The objective of the work}

To determine the theoretical significance of the research problem, review the literature, and define the key concept of the research, we used theoretical methods: analysis, synthesis, modeling. Pedagogical experiment was chosen as the leading research method which was applied in order to identify the effectiveness of the proposed pedagogical conditions in the development of social and communicative competence of future teachers in the process of professional training.

\section{Materials and the results of the research}

The system of higher education in modern Russia is aimed at the professional training of highly qualified, competent teaching staff. Its content should be based on modern teaching technologies that graduates obtain during their learning process. For this, it is necessary to replace the reproductive-functional model of education with a professional-competence one. The analysis of scientific works indicates that the communicative competence we are studying is considered in the context of professional competence. It is needed to perform professional tasks in the context of multifunctional relationships and interactions. In these conditions, the need for specialists with a high level of development of social and communicative competence, who include future teachers, is extremely relevant and urgent.

The analysis of scientific and theoretical sources shows that the problem of the development of social and communicative competence of future teachers is in the field of vision of both foreign and domestic researchers. In particular, the pedagogical conditions and means for the development of the social and communicative potential of the individual are analyzed in the works of E.A. Shumilova [1, 2], I.V. Zotova, O. Yu. Butvin [3]. Methodological problems of communication are considered in the works of Hanh thi Nguyen [4], N. Lukyanova et al. [5], M. Raitina [6]. Various aspects of professional communication are studied in the scientific works of E.V. Vezetiu [7], K.E. Bezukladnikov, M.A. Novosyolov, B.A. Kruze [8]. The preparation of future teachers for professional activity was studied in the works of N.A. Gluzman, N.V. Gorbunova [9], M. Sirotová [10].

In the works of foreign and domestic authors, various approaches to the problem of interpersonal interaction and communication are disclosed: cultural (M.A. Zubkova and others) [12]; social (N.Yu. Belikova and others) [13]; systemic (M. Raitina [14], C.J. Nölle [15]); ethnocultural (I.M. Degil [16], VD Popkova [17], TG Stefanenko [18]). Communication is a complex multidimensional process of establishing and developing contacts between people, generated by the needs of joint activities and including the exchange of information, the development of a single strategy of interaction, perception and understanding of another person.

Comprehension of the essence as well as the structure of social and communicative competence makes it possible to understand what conditions are necessary for the process of its effective development among future teachers. The process of developing social and 
communicative competence among future teachers within the framework of this study is considered as a purposeful influence on the personality of a student at a university. It is also assumed that the trainer in the learning process will additionally process the information received, passing it through himself. At this stage, the processes of one's own personal activity are stimulated, implying continuous work on oneself and self-development. In accordance with this position, the future teacher is perceived not only as a subject of educational and professional activity, but also as a subject of constant active selfdevelopment. The teaching profession differs from many in that constantly evolving component that is not present in all professions. Students of the pedagogical direction of training should be aware of the need for constant self-improvement and self-development in their future profession, without which it is impossible to achieve the desired results of professional activity.

Thus, summarizing the research on the formation of the development of social and communicative competence among future teachers, we can conclude that the following pedagogical conditions should be applied:

- subjects of educational process understand the development of social and communicative competence as the teacher's readiness to organize interaction and skills of interpersonal communication with students within the framework of a humanistically oriented educational process, understood as a complex structural formation which includes a number of components (motivational-value, information-content and practice-oriented);

- educational process at the university is accompanied by active interpersonal communication and interaction between the teacher and the student;

- practical application of humane value guidelines in relation to the personality of the student is experienced;

- the condition of organization of a purposeful process of developing social and communicative competence in future teachers using a specially developed set of classes is observed.

We have identified the following criteria with indicators of the development of social and communicative competence of a future teacher in the process of professional training: motivational-value, information-content and practice-oriented.

The content of these criteria is revealed using the following indicators. Indicators of the motivational and value criterion: the development of an increased interest in social and communicative activities, the desire to achieve a high level of professional training; conviction in the need to form positive personality traits in oneself and the desire to overcome such traits that are contraindicated in the profession of a teacher; the need to improve professional skills, content and methodology for the formation of pedagogical communication skills, the desire for social interaction; the formation of convictions of a humane attitude towards the younger generation as the highest value of society, ensuring the spiritual growth of the future teacher, socialization and general development in the process of professional training.

Indicators of information-content criterion are as follows: knowledge of philosophical, psychological and pedagogical provisions about a person as the highest value of society, about the role of communication in personality development in society; formation of pedagogical thinking; knowledge of features of content and implementation of social and communicative activities, methods of analyzing interpersonal communication, determining the degree of its effectiveness, correcting the pedagogical impact on the team and personality of the child; willingness to update their knowledge of interpersonal communication, mastering modern concepts and theories of learning; formation of future teachers' skills to combine creative abilities of the younger generation with their reproductive activity in the process of social and communicative activity. 
Indicators of a practice-oriented criterion include the following: students' possession of an integral complex of generalized psychological, pedagogical, social and communicative skills and abilities; possession of diagnostics of real results of the level of social and communication skills formed in children; readiness for the creative use of forms, methods, means of interpersonal communication skills and the desire for social interaction; development of students' sustainable interest and need for continuous replenishment of knowledge and skills, experience of social and communication activities with the environment.

To improve the preparation of a future teacher for the development of social and communicative competence, it is necessary to eliminate the discrepancy between the characteristics of a professionally trained teacher as an ideal model and the still imperfect state of social and communicative knowledge, skills and abilities among specialists of the teacher educational profile. For this, it is important to determine didactic ways and means, the implementation of which will eliminate the discrepancy and raise preparation of future teachers in higher education for the development of social and communicative competence in the process of professional training to a qualitatively new level.

The level of development of the social and communicative competence of a future teacher in the process of control assessment was carried out according to the methodology developed to determine the initial level of development of the social and communicative competence of future teachers. The development of social and communicative competence of future teachers was assessed according to three criteria: motivational value, informational content and practice-oriented. The control assessment made it possible to identify the dynamics of the development of social and communicative competence of future teachers in the direction of training pedagogical education.

Experimental work made it possible to reveal a positive dynamics in the change in the actual level of the development of social and communicative competence of future teachers in the process of professional training.

Table 1. Comparative analysis of the results of the development of social and communicative competence in future teachers.

\begin{tabular}{|c|c|c|c|c|c|c|c|}
\hline \multirow{3}{*}{$\begin{array}{c}\text { № } \\
\Pi / \Pi\end{array}$} & \multirow{3}{*}{ Name of criteria } & \multicolumn{6}{|c|}{ Levels (\%) } \\
\hline & & \multicolumn{2}{|c|}{ High } & \multicolumn{2}{|c|}{ Medium } & \multicolumn{2}{|c|}{ Low } \\
\hline & & Asc. & Contr. & Asc. & Contr. & Asc. & Контр. \\
\hline 1. & Motivational value & 10 & 60 & 40 & 30 & 50 & 10 \\
\hline 2. & Informative & 5 & 55 & 50 & 40 & 45 & 5 \\
\hline 3. & Practice-oriented & 0 & 65 & 45 & 35 & 55 & 0 \\
\hline
\end{tabular}

For greater clarity, Figure 1 shows the dynamics of increasing the level of development of the social and communicative competence of future teachers in the process of professional training. 


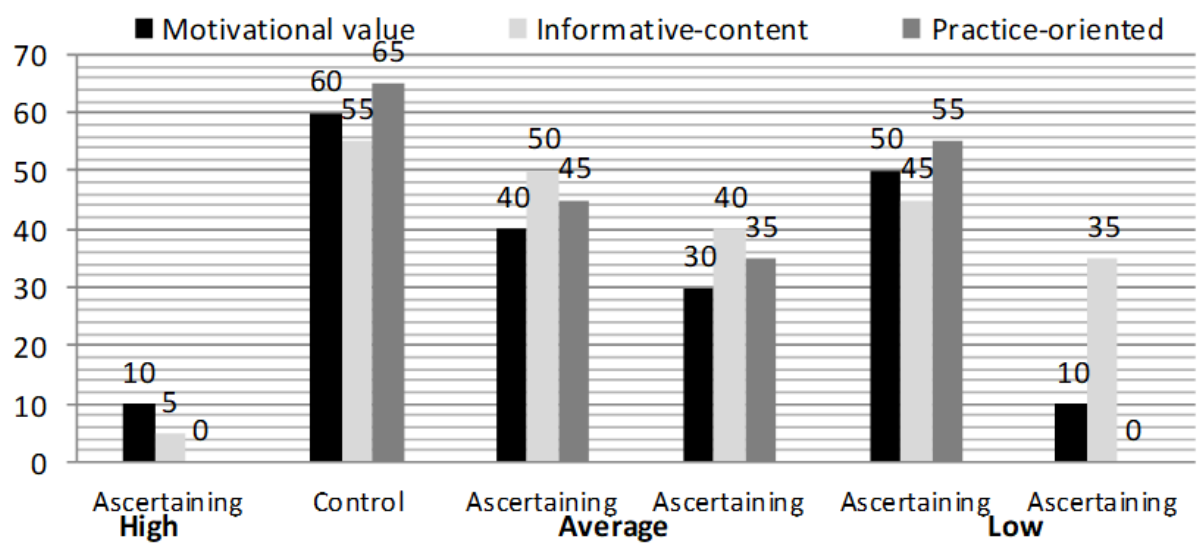

Fig. 1 - Comparative diagram of the ascertaining and control sections of the development of social and communicative competence in future teachers in the process of professional training.

As a result of the experimental work, the average value of a high level increased by $55 \%$ according to three criteria (motivational-value, information-content and practiceoriented). The average value of the average level of development of the social and communicative competence of future teachers increased by $10 \%$ according to three criteria. The average value of the low level of development of the social and communicative competence of future teachers has decreased by $45 \%$ according to three criteria.

Observations, a survey of students' practical activities showed a positive trend. The final diagnostics showed the following.

\section{Conclusions}

A teacher with higher education on the profile of pedagogy with a high level of development of social and communicative competence has the following knowledge and abilities to organize interaction between colleagues and students, as well as the skills of interpersonal communication and the desire for social interaction, meets the pedagogical requirements: knowledge of the methodological foundations and categories of pedagogy, patterns of the development and formation of students' personalities; knowledge of the conceptual foundations and principles of socialization of students; the ability to analyze and assess the state of pedagogical phenomena, causes, conditions and the nature of their occurrence; the ability to use innovative teaching and education methods; the ability to analyze the strengths and weaknesses of oneself and one's activities. So, in the course of the experimental work, the effectiveness of the revealed pedagogical conditions for the development of social and communicative competence in a future teacher in the process of professional training was proved.

\section{References}

1. E.A. Shumilova, Socio-communicative competence as a subject of research, 150-154 (2006)

2. E.A. Shumilova, Organizational and pedagogical conditions for the formation of social and communicative competence of future teachers, 21-27 (2014)

3. I.V. Zotova, O. Yu. Butvina, Preparing future educators for the formation of social and communicative competence of preschoolers, 111-113 (2020) 
4. Hanh thi Nguyen, Social interaction and competence development: Learning the structural organization of a communicative practice, 127-142 (2012)

5. N. Lukyanova, Y. Daneykin, N. Daneikina, Communicative Competence Management Approaches in Higher Education, 565-570 (2015)

6. M. Raitina, Transformation of Subject-centered Concepts of Scientific Creativity in Conditions of Communicative Sociality, 578-582 (2015)

7. E.V. Vesetiu, Formation of facilitative competence of future teachers as a condition of the humanistic paradigm of education, 80-82, (2019)

8. K.E. Bezukladnikov, M.A. Novosyolov, B.A. Kruze, The International Teacher's Foreign Language Professional Communicative Competency Development, 329-332 (2014)

9. N.A. Gluzman, N.V. Gorbunova, Professionalism of a teacher. Success and career: monograph, 311 (2019)

10. M. Sirotová, Pedagogical Praxis as a Process of Developing Professional Competencies in University Education of Future Teachers, 529-534 (2016)

11. T.N. Sinenko, The ability of the future teacher to interpersonal interaction in professional activity: essential characteristics, 78-82 (2012)

12. M.A. Zubkova, N.YU. Fominykh, E.N. Baranova, L.I. Abbasova, A.O. Pirozhkova, A.V. Bubenchikova, SH.M. Maigeldieva, Approaches to the future engineers foreign communicative culture formation, 781-786 (2019)

13. N.Yu. Belikova, E.U. Ponomareva, V.V. Kotlyarova, S.V. Yushina, L.I. Abbasova, A.T. Latysheva, Professional and social self-determination of youth under conditions of the modernization of higher education, 846-859 (2020)

14. M. Raitina, Communicative Strategies of Philosophical Education in Masters' Training, 440-444 (2015)

15. J. Nölle, M. Staib, R. Fusaroli, K. Tylén, The emergence of systematicity: How environmental and communicative factors shape a novel communication system, 93104 (2018)

16. I.M. Degil, J.-Claude Régnierb The Content of Spiritual and Religious Component of the Communicative Competence, 193-198 (2014)

17. V. D. Popkov, Stereotypes and Prejudices: Their Impact on the Process of Intercultural Communication, 178-191 (2002)

18. T.G. Stefanenko, Ethnic Identity: From Ethnology to Social Psychology, 3-17 (2009) 